Article

\title{
Gaussian Process Prediction Model to Estimate Excess Adsorption Capacity of Supercritical $\mathrm{CO}_{2}$
}

\author{
Narjes Nabipour ${ }^{1}$, Sultan Noman Qasem ${ }^{2,3}$, Amir Mosavi ${ }^{4,5}$, Shahaboddin Shamshirband ${ }^{4,5 *}$ \\ ${ }^{1}$ Institute of Research and Development, Duy Tan University, Da Nang 550000, Vietnam; \\ narjesnabipour@duytan.edu.vn \\ ${ }^{2}$ Computer Science Department, College of Computer and information Sciences, Al Imam Mohammad Ibn \\ Saud Islamic University (IMSIU), Riyadh, Saudi Arabia \\ ${ }^{3}$ Computer Science Department, Faculty of Applied Science, Taiz University, Taiz, Yemen; \\ snmohammed@imamu.edu.sa \\ ${ }^{4}$ Queensland University of Technology, Faculty of Health, 130 Victoria Park Road, Queensland 4059, \\ Australia \\ ${ }^{5}$ Institute of Structural Mechanics, Bauhaus University Weimar, D-99423 Weimar, Germany; \\ amir.mosavi@uni-weimar.de \\ ${ }^{6}$ School of the Built Environment, Oxford Brookes University, Oxford OX3 0BP, UK;a.mosavi@brookes.ac.uk \\ ${ }^{7}$ Department for Management of Science and Technology Development, Ton Duc Thang University, Ho Chi \\ Minh City, Viet Nam; shahaboddin.shamshirband@tdtu.edu.vn \\ ${ }^{8}$ Faculty of Information Technology, Ton Duc Thang University, Ho Chi Minh City, Viet Nam \\ Corresponding: shahaboddin.shamshirband@tdtu.edu.vn
}

\begin{abstract}
Deep coal beds have been suggested as possible usable underground geological locations for carbon dioxide storage. Furthermore, injecting carbon dioxide into coal beds can improve the methane recovery. Due to importance of this issue, a novel investigation has been done on adsorption of carbon dioxide on various types of coal seam. This study has proposed four types of Gaussian Process Regression (GPR) approaches with different kernel functions to estimate excess adsorption of carbon dioxide in terms of temperature, pressure and composition of coal seams. The comparison of GPR outputs and actual excess adsorption expresses that proposed models have interesting accuracy and also the Exponential GPR approach has better performance than other ones. For this structure, $R 2=1, \mathrm{MRE}=0.01542, \mathrm{MSE}=0, \mathrm{RMSE}=0.00019$ and $\mathrm{STD}=0.00014$ have been determined. Additionally, the impacts of effective parameters on excess adsorption capacity have been studied for the first time in literature. According to these results, the present work has valuable and useful tools for petroleum and chemical engineers who dealing with enhancement of recovery and environment protection.
\end{abstract}

Keywords: coal; supercritical $\mathrm{CO}_{2}$; Gaussian process regression; machine learning; adsorption model

\section{Introduction}

The Global Carbon Project declares that overall emission of $\mathrm{CO}_{2}$ has been grown to 37 billion tones based on the latest annual evaluation[1]. This growth causes significant effects on global warming and rising sea levels which threat the human future. Various actions are required to decrease the $\mathrm{CO}_{2}$ concentrations in the atmosphere such as injection of carbon dioxide into deep coal seams. The geological sequestration of $\mathrm{CO}_{2}$ is not only purpose of this injection but enhancement of the methane recovery from coal seams [2-5]. After injection of $\mathrm{CO} 2$ into the deep coal seems, it can be easily situated in supercritical condition $\left(\mathrm{T}>31.04{ }^{\circ} \mathrm{C}, \mathrm{P}>7.38 \mathrm{MPa}\right)$. The supercritical $\mathrm{CO}_{2}$ have complex 
behaviors in flowing through the coal seams including adsorption behavior, seepage behavior, mechanical weakening and microstructure variance effects (see Figure 1). The flow of $\mathrm{CO}_{2}$ through the coal seams will cause some changes in pore pressure and exerted stress on the coal seams. $\mathrm{CH}_{4}$ will be pushed by $\mathrm{CO}_{2}$ in competitive adsorption within the affected zone. During this process, the $\mathrm{CO}_{2}$ pressure will reduce gradually and also desorption will occur. The changes in desorption and adsorption of $\mathrm{CH}_{4}$ and $\mathrm{CO}_{2}$ can affect the volume deformation and mechanical properties of coal[6]. Furthermore, these changes will influence the $\mathrm{CO}_{2}$ seepage properties from the coal seams. Thus, $\mathrm{CO}_{2}$ injection can be considered as a complicated process dealing with various mechanisms combined with each other. The investigation of adsorption of $\mathrm{CO}_{2}$ and $\mathrm{CH}_{4}$ among the aforementioned mechanisms have the great role because the value of greenhouse gas storage of deep coal beds can be determined through this investigation.

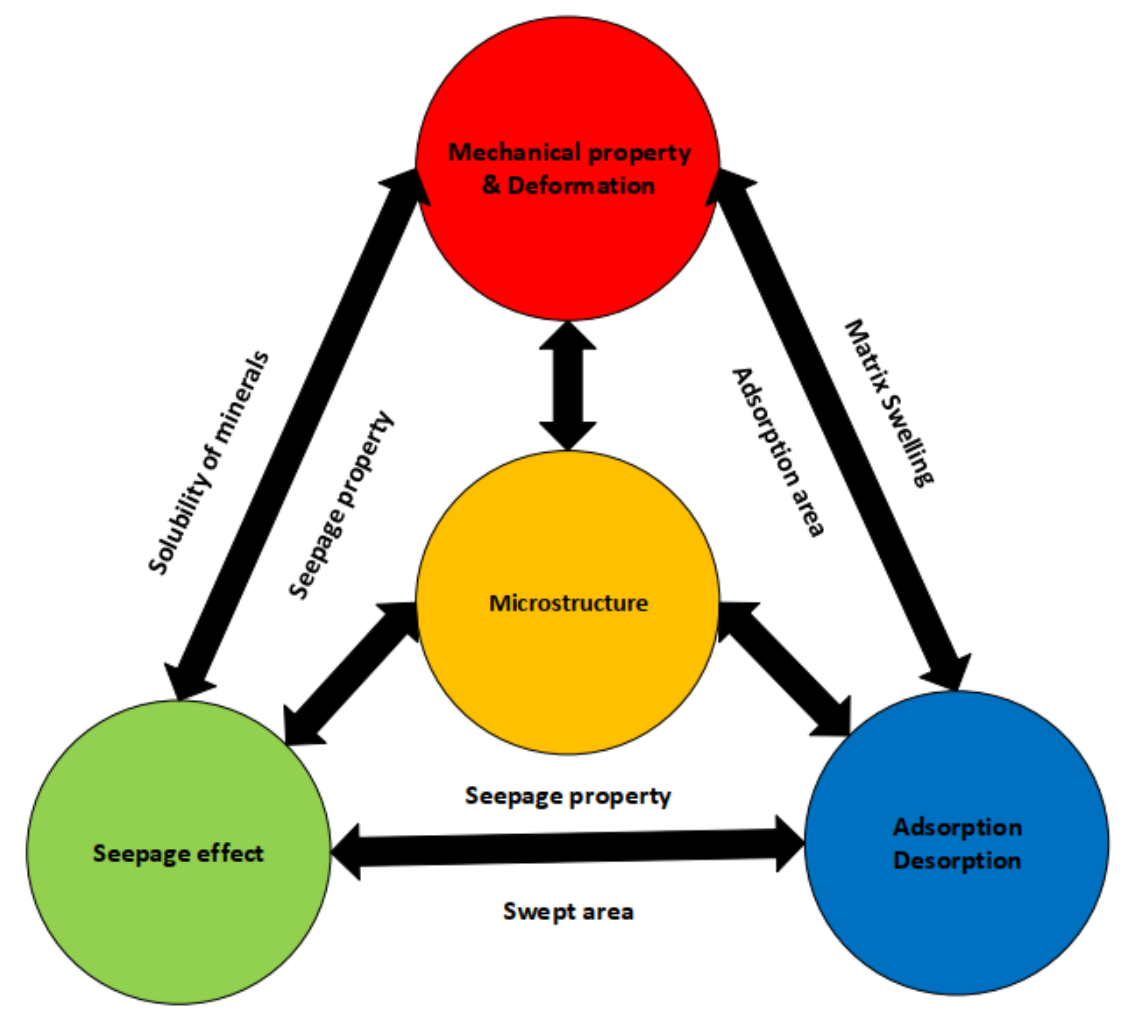

Fig. 1: Multi-factor combining impact of interaction of coal bed and $\mathrm{CO}_{2}[5]$

There are several researches about the $\mathrm{CO}_{2}$ adsorption on coal. For example, Ramasamy and coworkers investigated the $\mathrm{CO}_{2}$ adsorption on various kinds of coal and concluded that the capacity of adsorption is highly function of coal properties[7]. After that, a new research was done on the competitive adsorption of $\mathrm{CH}_{4}$ and $\mathrm{CO}_{2}$ by Zhang to identify the impact of gas composition and depth on adsorption of $\mathrm{CO}_{2}$ and $\mathrm{CH}_{4[8]}$. De Silva investigated the $\mathrm{CO}_{2}$ behaviors with different coal beds and expressed that the equations of states have acceptable estimation for $\mathrm{CO}_{2}$ adsorption[9]. Then, Mazzotti implemented the adsorption study of $\mathrm{N}_{2}, \mathrm{CH}_{4}$ and $\mathrm{CO}_{2}$ on coal and claimed that $\mathrm{CO}_{2}$ has better adsorption than $\mathrm{N}_{2}$ and $\mathrm{CH}_{4}[4]$.

Although there is a wide investigation on the $\mathrm{CO}_{2}$ adsorption on coal seems, the experimental study on $\mathrm{CO}_{2}$ adsorption on coal in the supercritical conditions faces many difficulties and measured 
phenomena are not consistent. Kim et al. and Li et al. have investigated the adsorption capacity of coal beds so that they expressed that amount of $\mathrm{CO}_{2}$ and $\mathrm{CH}_{4}$ adsorption rises at the subcritical conditions, while there is a maximum adsorption under the supercritical conditions as pressure increases[10,11]. Bae et al. expressed that the pressure of maximum adsorption value reduces by increasing temperature[12]. Krooss point out that the adsorption capacity rises by temperature in low-pressure conditions. The temperature has complex effects on adsorption under high pressure[13]. Tang et al. expressed that some scholars exhibit special test phenomena in supercritical $\mathrm{CO}_{2}$ adsorption, whereas others show smooth isotherms of $\mathrm{CO}_{2}$ excess adsorption[12-21]. Thus, considering the growth of injection of $\mathrm{CO}_{2}$ into coals and their heterogeneous properties, the investigation of supercritical $\mathrm{CO}_{2}$ adsorption requires more investigations to clarify the mechanisms of $\mathrm{CO}_{2}$ sequestration in coal bed.

In the recent years, the computational study of $\mathrm{CO}_{2}$ adsorption on coals has attracted attention of many recent scholars[12,20,22]. These studies commonly include monolayer, multilayer and potential models. The typical monolayer models are the Toth, Langmuir, T-P, and Extended-Langmuir models. The multilayer approach includes different forms of BET models and also the potential model consists of D-R model, its modification and upgraded D-A model. These approaches have been utilized for estimation of adsorption of supercritical $\mathrm{CO}_{2}$. However, they have significant drawbacks including limitations to a specific coal seams or isothermal conditions. Due to this fact, development of a comprehensive adsorption model which overcomes the limitations of different conditions (temperature, pressure and coal type) becomes necessary.

In the current work, the amount of excess $\mathrm{CO}_{2}$ adsorption on various kinds of coal samples has been predicted by proposing Gaussian Process Regression approaches including four different kernel functions. Furthermore, the impacts of pressure, temperature and composition on $\mathrm{CO}_{2}$ adsorption on coal seams have been investigated.

\section{Methodology}

2.1. Data gathering

To develop a comprehensive approach for calculation of excess $\mathrm{CO}_{2}$ adsorption on coal seams, an actual $\mathrm{CO}_{2}$ adsorption databank has been collected from various resources $[5,11,17,19,20,22]$. This dataset includes 394 actual adsorption points for 16 various coalbeds in temperature range of 20.14 to $79.42{ }^{\circ} \mathrm{C}$ and pressure range of 0.048 and $22.887 \mathrm{MPa}$. The excess adsorption $\mathrm{CO}_{2}$ values for these conditions vary between 0.09325 and $2.41588 \mathrm{mmol} / \mathrm{g}$.

\subsection{Gaussian Process Regression}

One of the non-parametric approaches is Gaussian Process Regression (GPR) which has ability of modeling arbitrary complicated systems. In the most of estimation issues, this algorithm is preferred because of its flexibility in providing the uncertainty descriptions[23]. This approach models series of time by using a covariance function (CovF) $k\left(x, x^{\prime}\right)$ and mean function $(M F) m(x)$ as shown in following:

$y=f(x) \sim N\left(m(x), k\left(x, x^{\prime}\right)\right.$ 
In which, $y$ and $x$ are output and input of training set and $f(x)$ point to the latent variable of model. Usually, the mean function of aforementioned equation is selected to zero in the most applications. CovF which expresses the similarities among inputs, is known as the main parameter in GPR because the data points with same values of $x$ are likely to have same output. In this study, different forms of kernel function have been used as following:

- Squared Exponential:

$k\left(x, x^{\prime}\right)=\theta_{1}^{2} \exp \left(-\frac{d^{2}}{2 \theta_{2}^{2}}\right)$

where $\theta_{1}$ and $\theta_{2}$ are hyper-parameters which require to be optimized and $\mathrm{d}$ shows the Euclidean distance between $\mathrm{x}$ and $x^{\prime}$.

- Exponential

$k\left(x, x^{\prime}\right)=\theta_{1}^{2} \exp \left(-\frac{r}{\theta_{2}}\right)$

$r=\sqrt{\left(x-x^{\prime}\right)^{T}\left(x-x^{\prime}\right)}$

- Rational Quadratic

$k\left(x, x^{\prime}\right)=\theta_{1}^{2}\left(1+\frac{r^{2}}{2 \propto \theta_{2}^{2}}\right)$

Where $\propto$ is a positive parameter of covariance.

- Matern

$k\left(x, x^{\prime}\right)=\frac{1}{\Gamma(v) 2^{v-1}}\left(\frac{\sqrt{2 v} r}{l}\right)^{v} K_{v}\left(\frac{\sqrt{2 v} r}{l}\right)$

Where $v$ and 1 are positive parameters and $K_{v}$ is known as modified Bessel function.

In the training of model, the hyper-parameters of kernel matrix $(\mathrm{K})$ are determined by minimizing the negative log marginalized likelihood (NLML):

$N L M L=-\log (p(y \mid x, \theta))=-\frac{1}{2} \log \left|K+\sigma_{n}^{2} I\right|-\frac{1}{2} y^{T}\left(K+\sigma_{n}^{2} I\right)^{-1} y-\frac{n}{2} \log (2 \pi)$

The NLML minimization concludes to determination of unknown $\theta$. The optimization problem for estimation of parameter can be written as following:

$\hat{\theta}=\underset{\theta}{\operatorname{argmin}}-\log (p(y \mid x, \theta))$

The NLML is optimized by applying off-the-shelf optimization approaches because it is a convex function. Then, the estimation distribution for testing data can be shown as below:

$f_{*} \mid x, y, x_{*} \sim N\left(\bar{f}_{*}, \operatorname{cov}\left(f_{*}\right)\right)$ 
$\overline{f_{*}}=m\left(x_{*}\right)+K\left(x, x_{*}\right)\left(K(x, x)+\sigma_{n}^{2} I\right)^{-1}(y-m(x))$

$\operatorname{cov}\left(\bar{f}_{*}\right)=K\left(x_{*}, x_{*}\right)-K\left(x_{*}, x\right)\left(K(x, x)+\sigma_{n}^{2} I\right)^{-1} K\left(x, x_{*}\right)$

In which, $\bar{f}_{*}$ point to estimation results and also $\operatorname{cov}\left(\bar{f}_{*}\right)$ is the estimation uncertainty. The average of GPR estimation distribution in equation 10 is linear function of targets of $y$ for training dataset when $\mathrm{m}(\mathrm{x})=0$. According to this fact, the average of estimation distribution is formulated as follows:

$\bar{f}_{*}=K\left(x, x_{*}\right)\left(K(x, x)+\sigma_{n}^{2} I\right)^{-1} y=W_{G P R} y$

In which, $W_{\text {GPR }}$ denotes the weighting matrix of GPR [23-25]. In order to better understand of proposing GPR algorithms for our work, a flowchart is depicted in Figure 2.

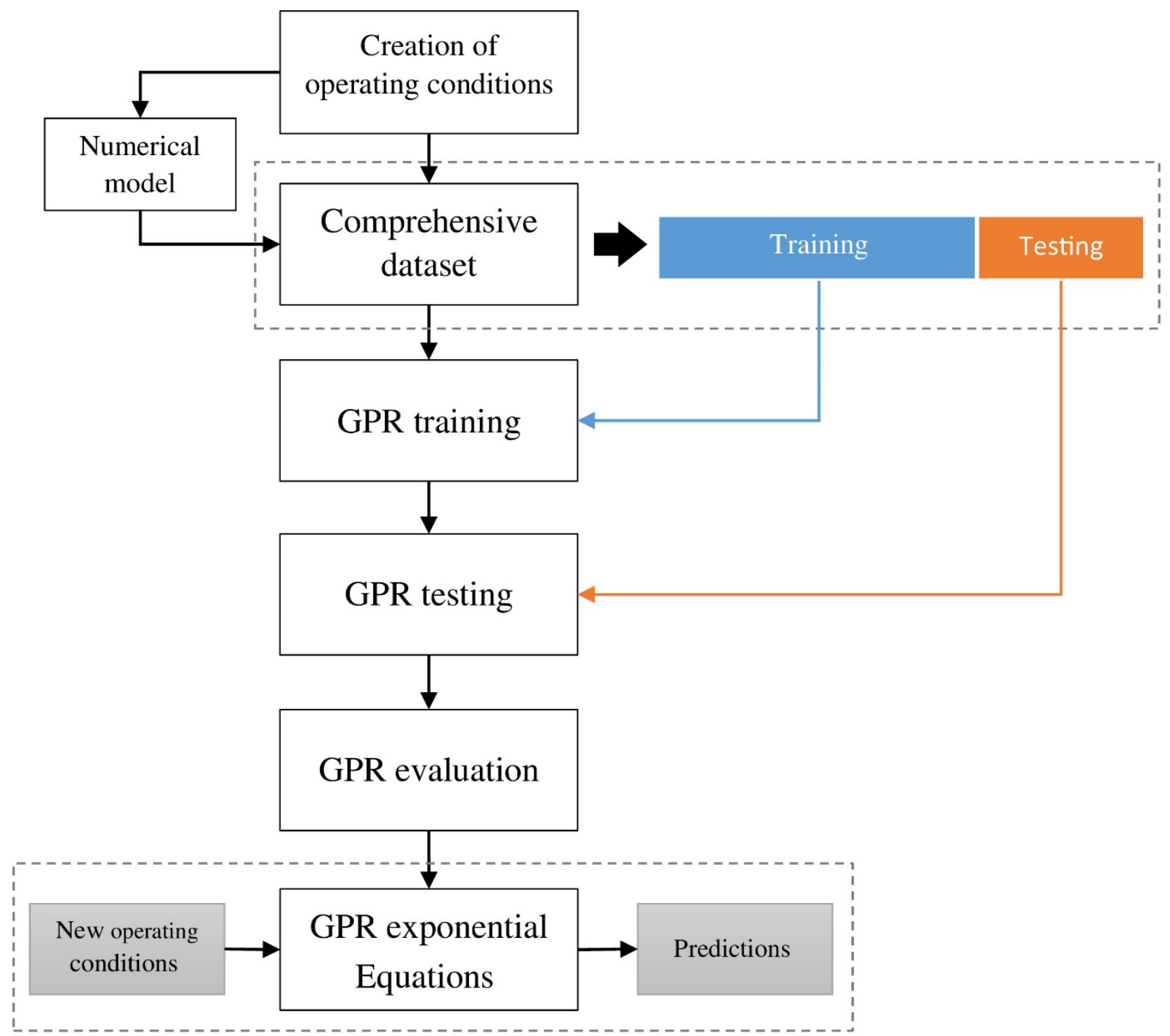

Fig. 2: Flowchart for Proposing GPR algorithms

\section{Results and discussion}

In this study, four different types of GPR algorithm have been suggested to estimate excess adsorption of $\mathrm{CO}_{2}$ on various coalbeds. The input variables of GPR algorithms have been selected as pressure, temperature, Ash, Moisture, volatile and fixed carbon contents of coalbeds. In order to 
assess the accuracy of GPR algorithms including four different kernel functions of Exponential, Square exponential, Matern and Rational Quadratic, statistical parameters have been determined by following definitions:

Mean relative error $(\mathrm{MRE})=\frac{100}{N} \sum_{i=1}^{N}\left(\frac{X_{i}^{\text {actual }}-X_{i}^{\text {predicted }}}{X_{i}^{\text {actual }}}\right)$

Root mean square error $(\mathrm{RMSE})=\sqrt{\frac{1}{N} \sum_{i=1}^{N}\left(\left(X_{i}^{\text {actual }}-X_{i}^{\text {predicted }}\right)^{2}\right)}$

Standard deviations $(\mathrm{STD})=\left(\frac{1}{N-1} \sum_{i=1}^{N}(\text { error }-\overline{\text { error }})\right)^{0.5}$

Mean squared error (MSE) $=\frac{1}{N} \sum_{i=1}^{N}\left(X_{i}^{\text {actual }}-X_{i}^{\text {predicted }}\right)^{2}$

R-squared $\left(\mathrm{R}^{2}\right)=1-\frac{\sum_{\mathrm{i}=1}^{\mathrm{N}}\left(\mathrm{X}_{\mathrm{i}}^{\text {actual }}-\mathrm{X}_{\mathrm{i}}^{\text {predicted }}\right)^{2}}{\sum_{\mathrm{i}=1}^{\mathrm{N}}\left(\mathrm{X}_{\mathrm{i}}^{\text {actual }}-\overline{\mathrm{X}^{\text {actual }}}\right)^{2}}$

As shown in Table 1, determined $\mathrm{R}^{2}$ values are 0.993, 1, 0.989 and 0.993 for Rational Quadratic, Exponential, Squared Exponential and Matern GPRs respectively. Due to this fact, Exponential kernel function has better performance than other functions. For this structure, MRE $=0.01542$, MSE $=0$, RMSE $=0.00019$ and STD $=0.00014$ have been determined. These low values of various errors express the ability of Exponential GPR in prediction of excess adsorption of $\mathrm{CO}_{2}$ on coalbeds.

Table 1. Statistical parameters for determination of $\mathrm{CO} 2$ adsorption on coal seams

\begin{tabular}{ccccccc}
\hline & & $\mathbf{R}^{2}$ & MRE (\%) & MSE & RMSE & STD \\
\hline GPR (Rational & Train & 0.992 & 3.42310 & 0.00204 & 0.04516 & 0.03755 \\
Quadratic) & Test & 0.996 & 3.17835 & 0.00105 & 0.03246 & 0.02552 \\
& Total & 0.993 & 3.36471 & 0.00180 & 0.03246 & 0.03509 \\
& Train & 1.000 & 0.01363 & 0.00000 & 0.00017 & 0.00014 \\
GPR (Exponential) & Test & 1.000 & 0.02115 & 0.00000 & 0.00019 & 0.00015 \\
& Total & 1.000 & 0.01542 & 0.00000 & 0.00019 & 0.00014 \\
& Train & 0.988 & 4.50007 & 0.00295 & 0.05431 & 0.04285 \\
GPR (Squared & Test & 0.993 & 4.16369 & 0.00176 & 0.04199 & 0.03159 \\
& Total & 0.989 & 4.41981 & 0.00267 & 0.04199 & 0.04048 \\
& Train & 0.992 & 3.23463 & 0.00188 & 0.04337 & 0.03636 \\
& Test & 0.996 & 3.08242 & 0.00098 & 0.03137 & 0.02439 \\
\hline GPR (Matern) & Total & 0.993 & 3.19832 & 0.00167 & 0.04082 & 0.03390 \\
\hline
\end{tabular}


On the other hand, for better judgement about discussing models, the simultaneous demonstration of estimated and experimental excess adsorption are depicted in Figure 3 for all four models. The interesting agreement between GPR outputs and actual excess adsorption is observed. Moreover, the regression or cross plot of actual and estimated excess adsorption are illustrated in Figure 4.


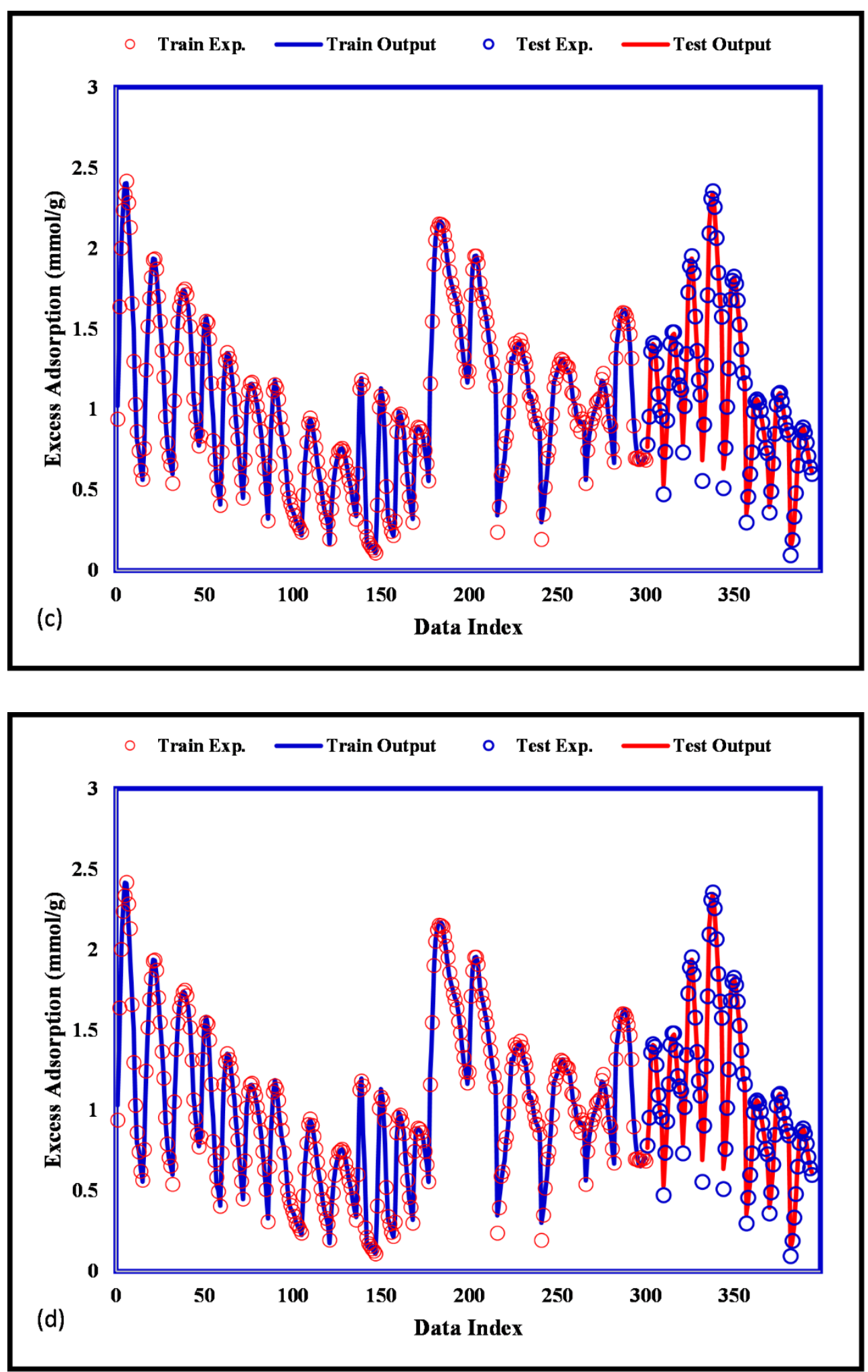

Fig. 3: Simultaneous comparison of predicted and experimental excess adsorption values for a) Exponential b) Square exponential c) Matern d) Rational Quadratic 

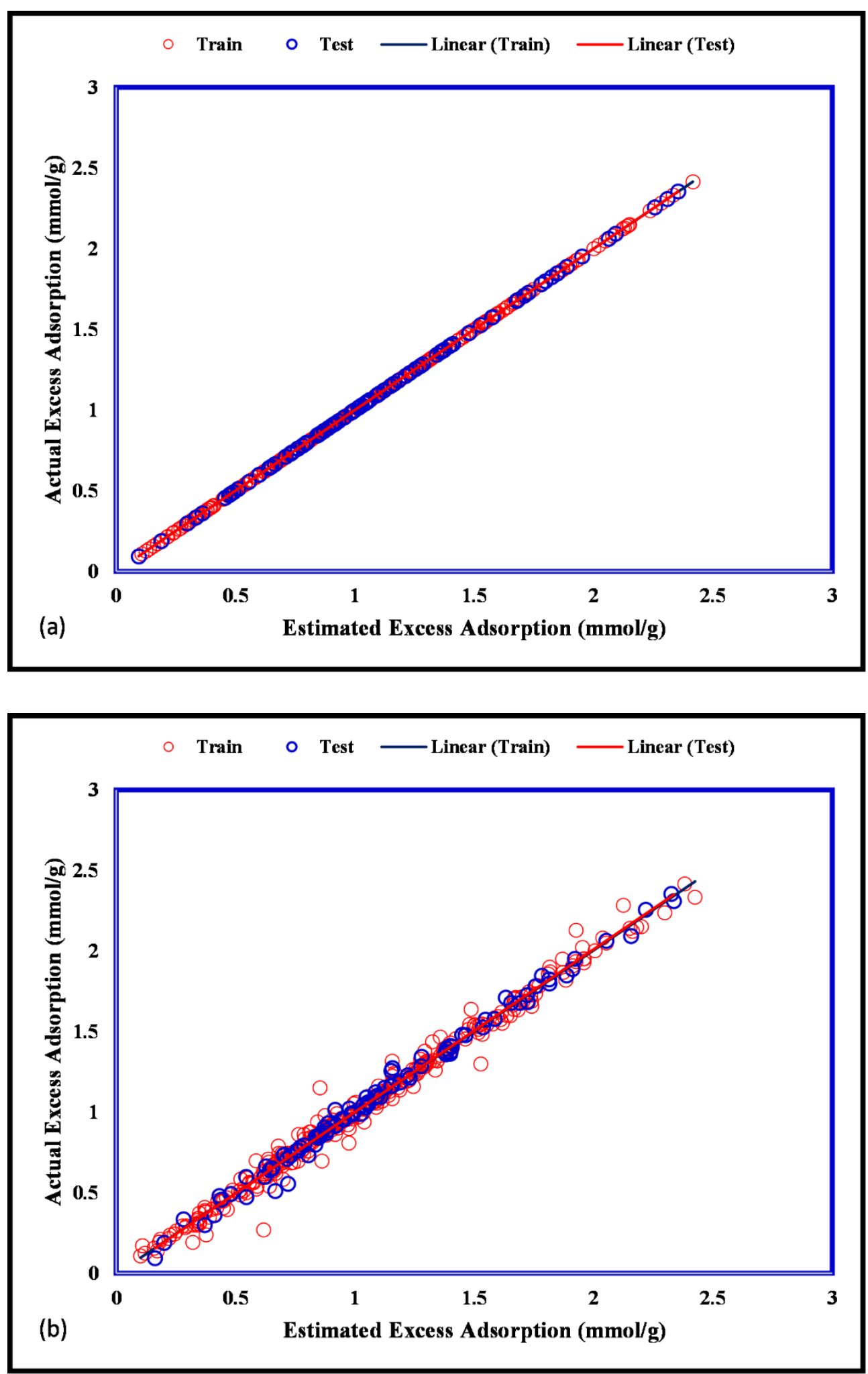

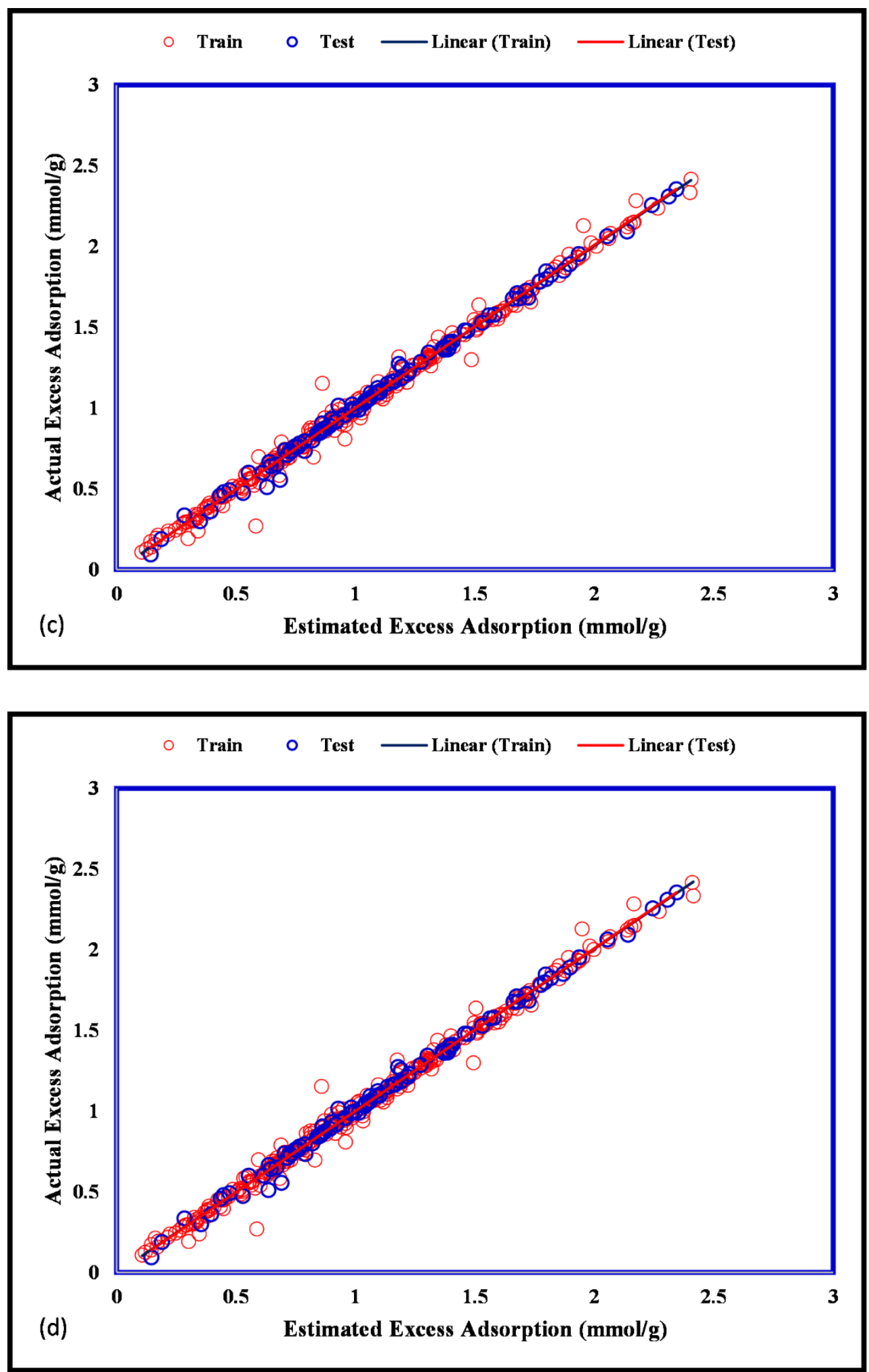

Fig. 4: Cross plots of actual and estimated excess adsorption values for a) Exponential b) Square exponential c) Matern d) Rational Quadratic

According to this analysis, the clouds of data points are located on bisector lines which express quality of GPR outputs. Additionally, the relative deviation between GPR output and actual excess adsorption has been determined and shown in Figure 5. 

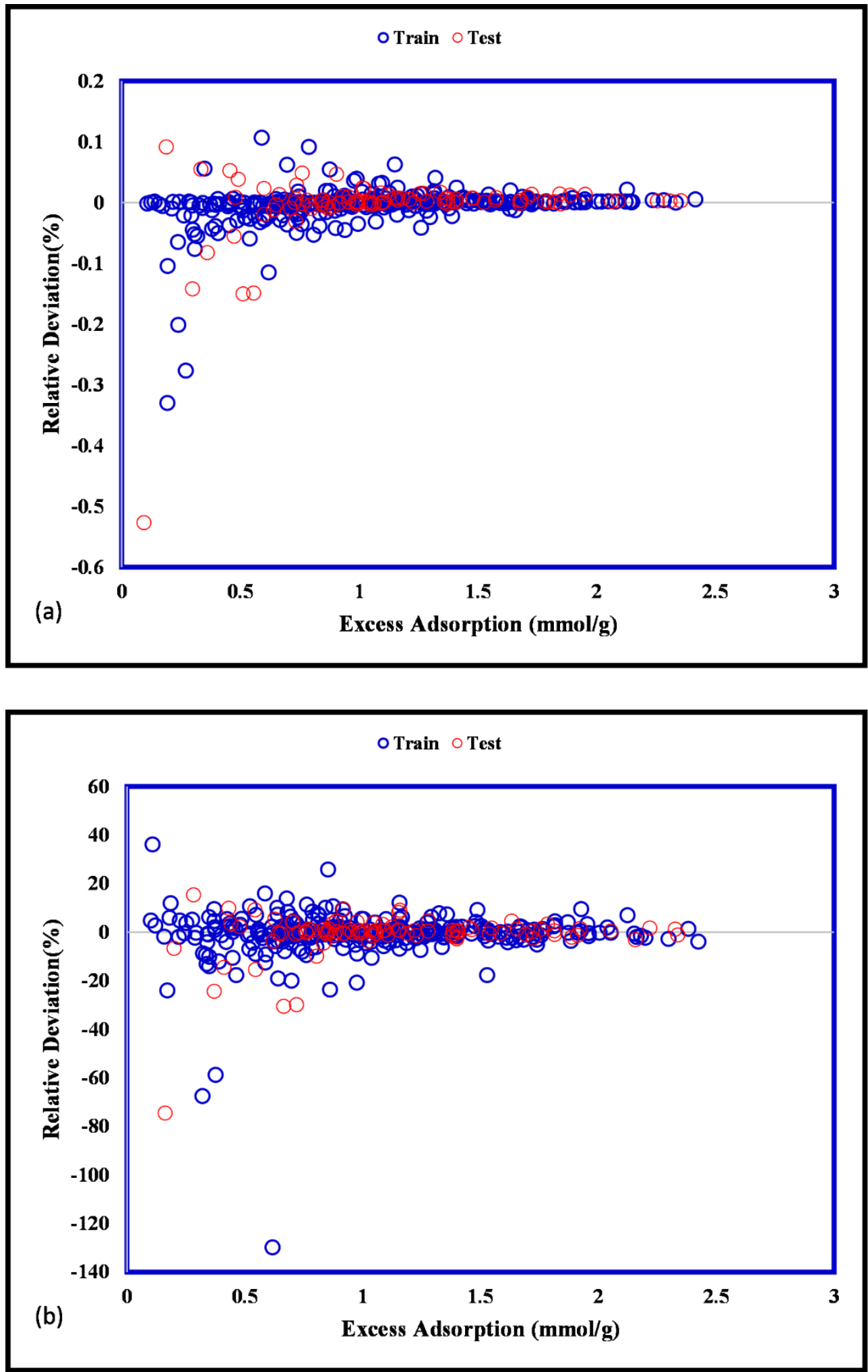

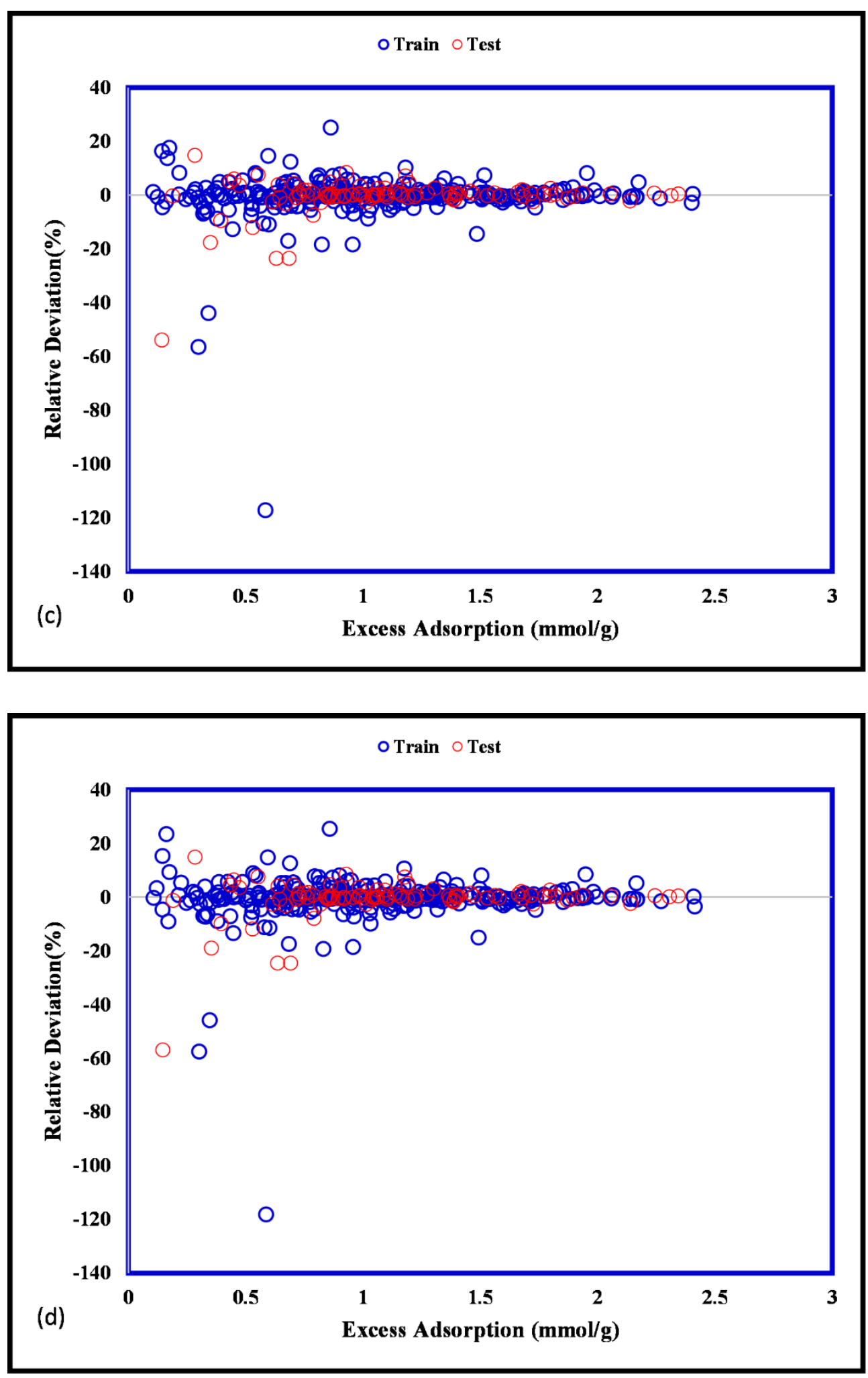

Fig. 5: Relative deviation between actual and estimated excess adsorption values for a) Exponential b) Square exponential c) Matern d) Rational Quadratic

The concentrations of relative errors near the zero line are considerable and also for better identification of concentration zone the histogram diagrams are depicted in Figure 6. According to the histograms, the most of frequencies of relative errors are near the zero point. 

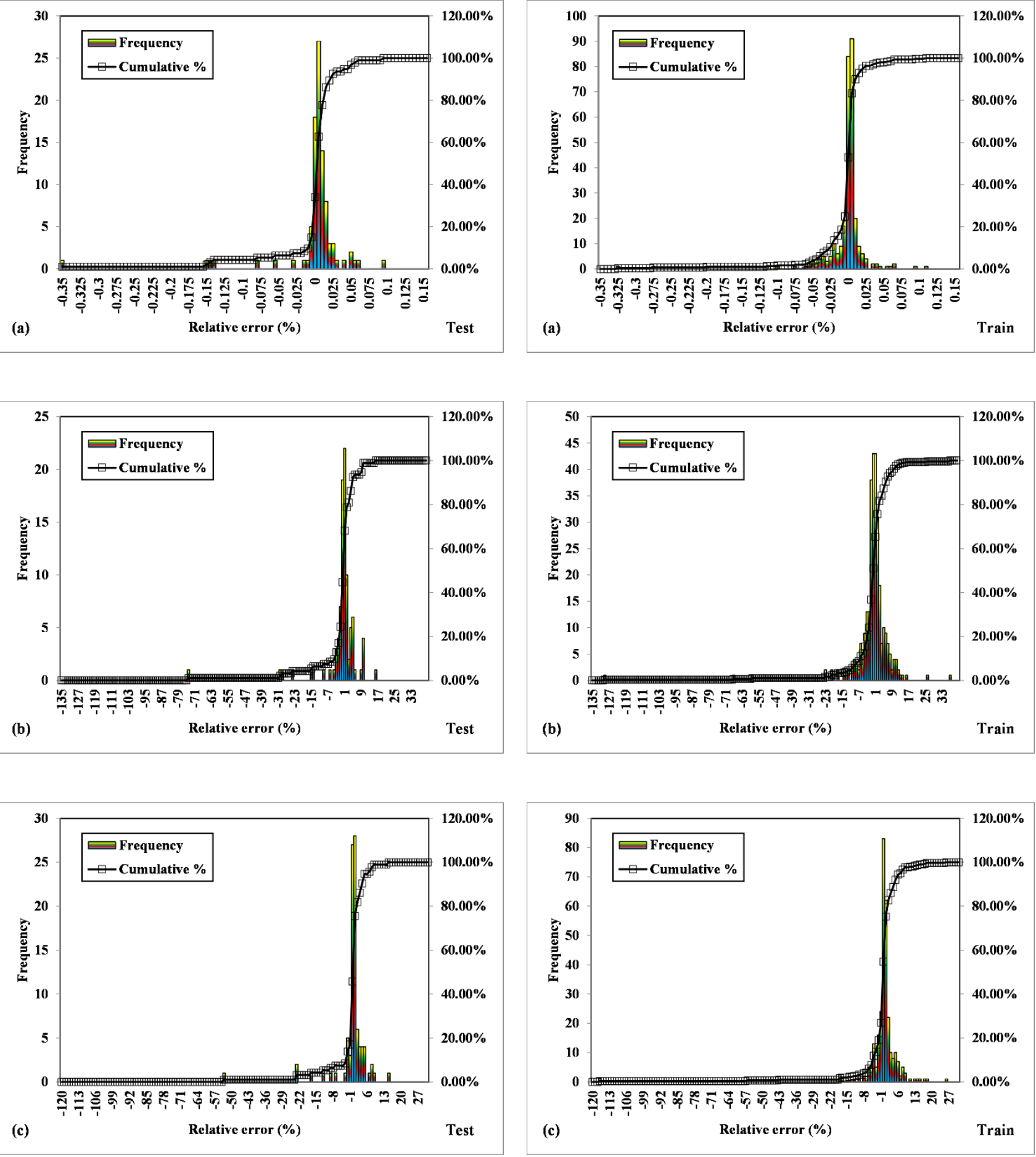

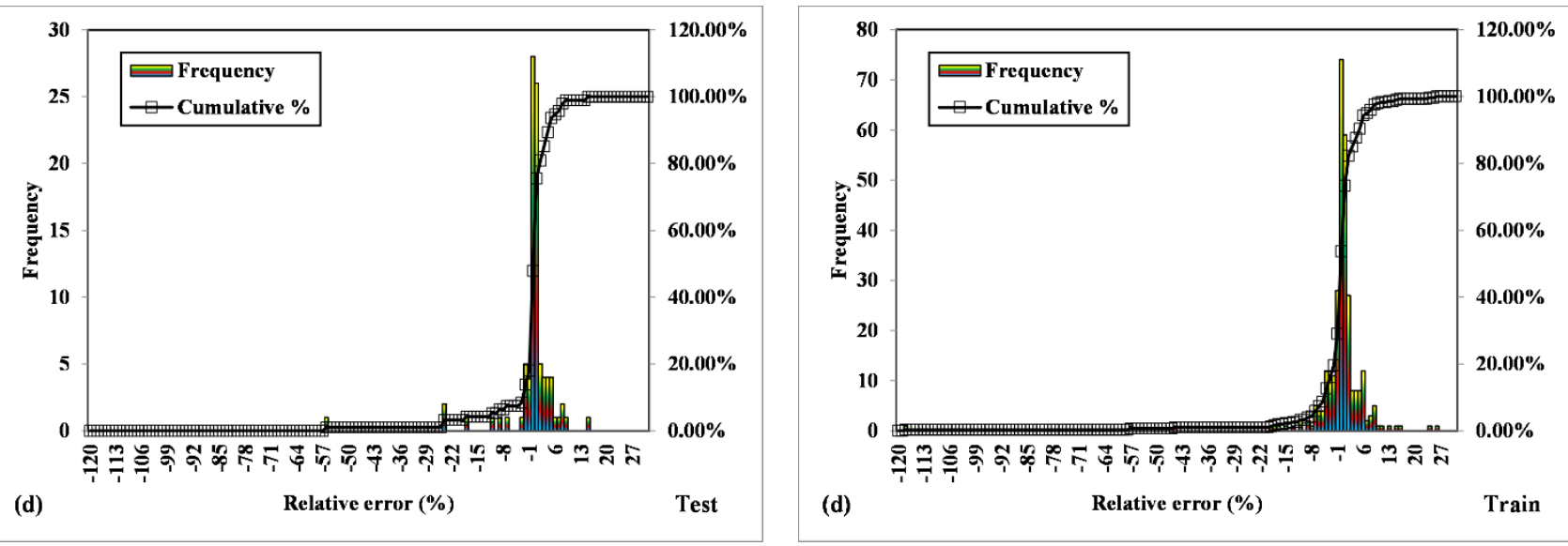

Fig. 6: Histogram diagrams of relative deviations for a) Exponential b) Square exponential c) Matern d) Rational Quadratic

The exactness of applied data points incredibly influences model validity. This investigation uses a considerable number of data points. It is worthy to mention that the data points may have some errors because of laboratory measurements. The suspected data or outliers are defined as separate points from general pattern of data points. To this end, development of powerful strategies to detect outliers is highly needed to remove inaccurate data and improve model precision. In this work, Leverage technique has been used to find suspected data. This technique determined residual values, after that, a Hat matrix is made based on the below formulation:

$H=U\left(U^{T} U\right)^{-1} U^{T}$

where $U$ is a matrix of $i^{*} j$ dimensional. $i$ and $j$ point to the number of model parameter and training points which are applied for calculation of critical leverage limit as below[26-28]:

$H^{*}=3(j+1) / i$

William's plot (see Figure 7) has potential to distinguish the suspected data visually which expresses the standardized residuals in terms of hat values. Subsequently, the green line point to the leverage limit and two red lines are standard residue limits. The data points which are located outside of the bounded area by these lines are known as suspected data. As can be seen in Figure 7, among 394 data point for Exponential, Square exponential, Matern and Rational Quadratic GPRs, 6, 4, 3 and 3 data points are considered as suspected data.

The proposed GPR algorithms construct a relationship between inputs and excess adsorption of $\mathrm{CO}_{2}$ on coal seams. Sensitivity analysis is normally used to study how input variables affect output. In order to detect the most effective variable on excess adsorption of $\mathrm{CO}_{2}$, Relevancy factor ( $\mathrm{r}$ ) is used. The range of this factor is between -1 and 1 , and also the more absolute $r$ expresses a more impact on the excess adsorption of $\mathrm{CO}_{2}$. Negative and positive values of $\mathrm{r}$ illustrate that the more the input the less and the more in the excess adsorption of $\mathrm{CO}_{2}$ respectively. The formulation of $\mathrm{r}$ can be described as following [29-33]: 
$r=\frac{\sum_{i=1}^{n}\left(X_{k, i}-\overline{X_{k}}\right)\left(Y_{i}-\bar{Y}\right)}{\sqrt{\sum_{i=1}^{n}\left(X_{k, i}-\overline{X_{k}}\right)^{2} \sum_{i=1}^{n}\left(Y_{i}-\bar{Y}\right)^{2}}}$

where $Y_{i}$ and $X_{k, i}$ denote the output and input. $\bar{Y}$ and $\overline{X_{k}}$ are known as averages of outputs and inputs. As shown in Figure 8, the higher pressure and Ash content, the lower excess adsorption of $\mathrm{CO}_{2}$. Moreover, temperature, Volatile, Moisture and Fixed carbon have straight relationships with target. Additionally, the most effective parameter on $\mathrm{CO}_{2}$ adsorption is Ash content.
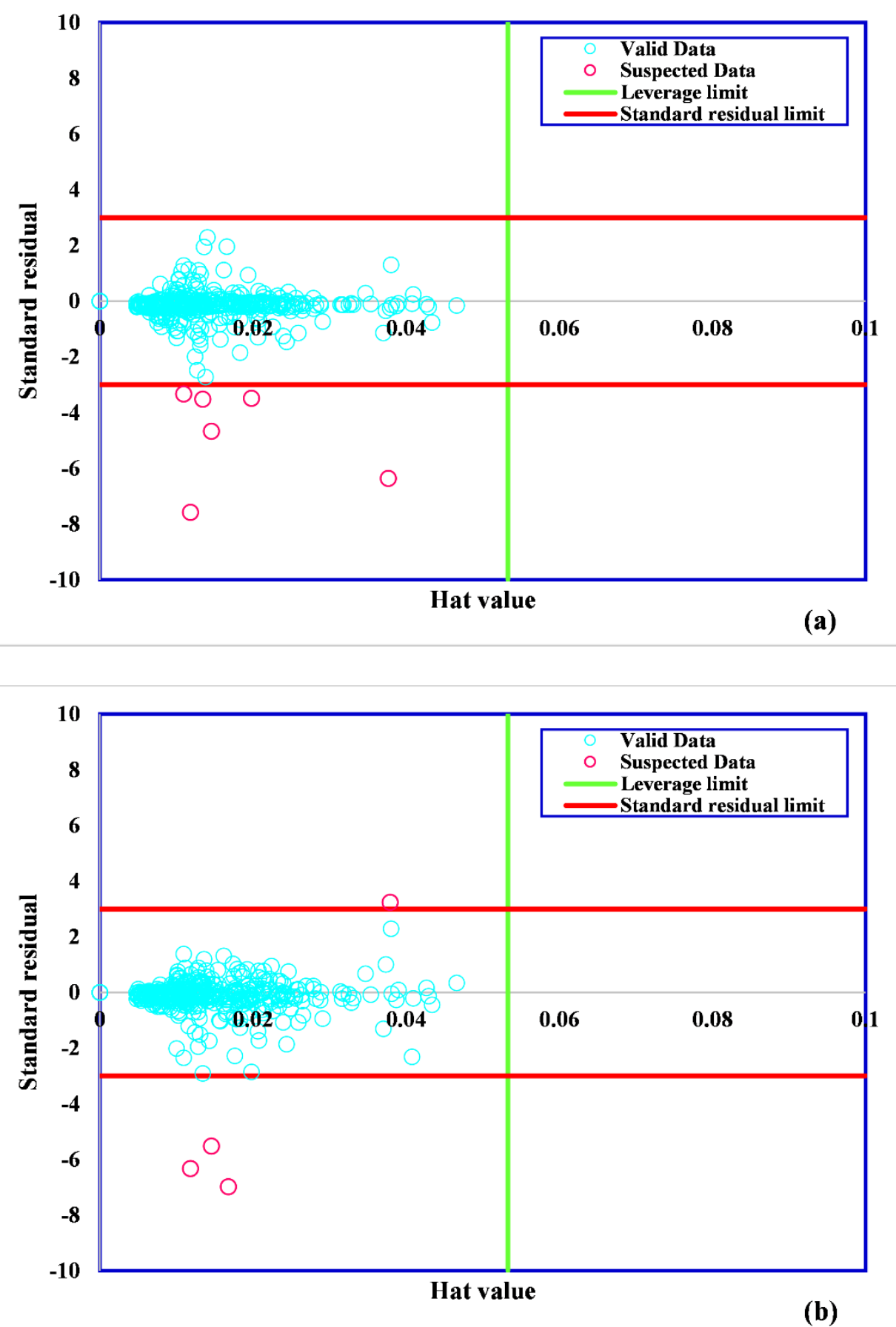

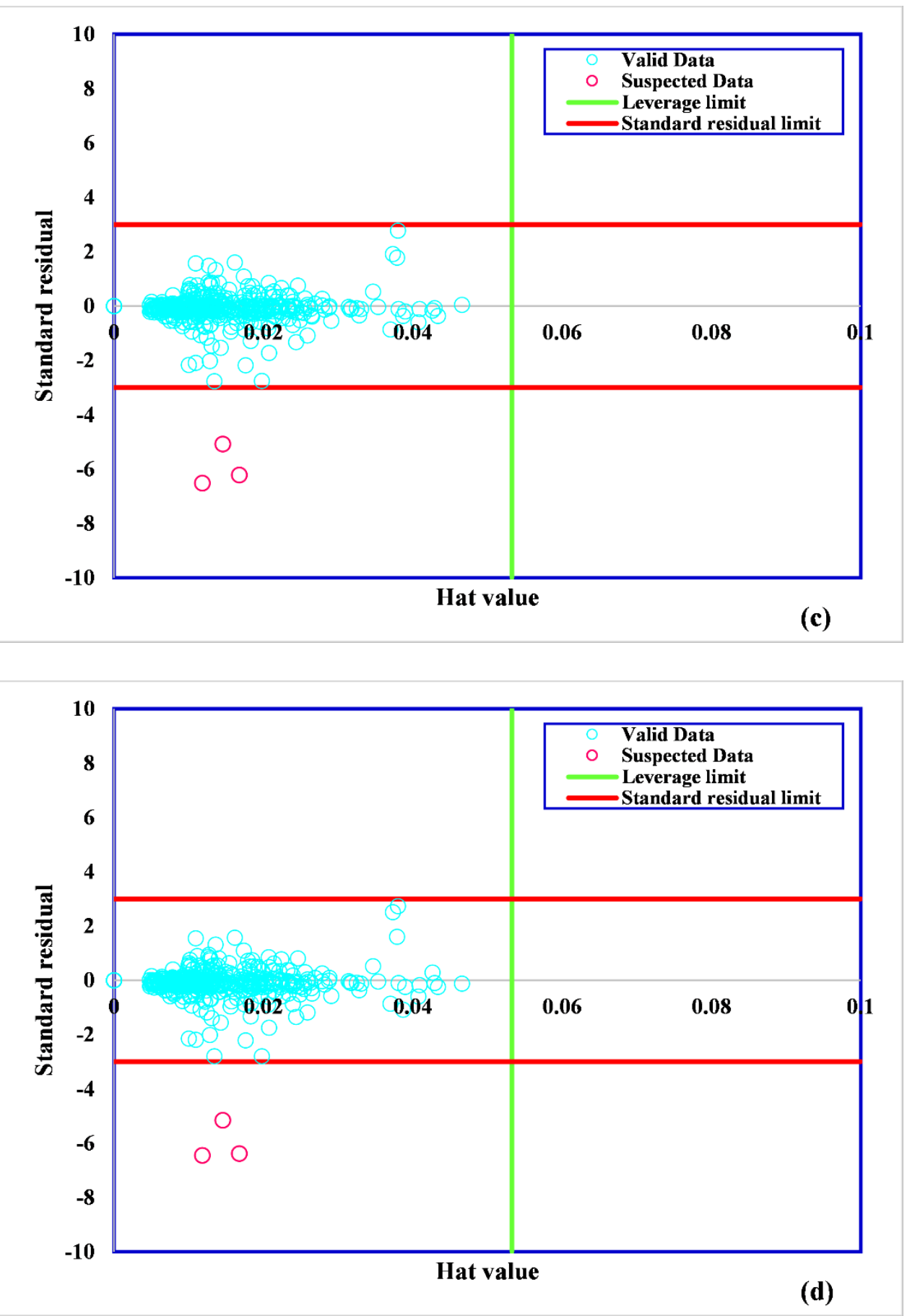

Fig. 7: Identification of outliers for a) Exponential b) Square exponential c) Matern d) Rational Quadratic 


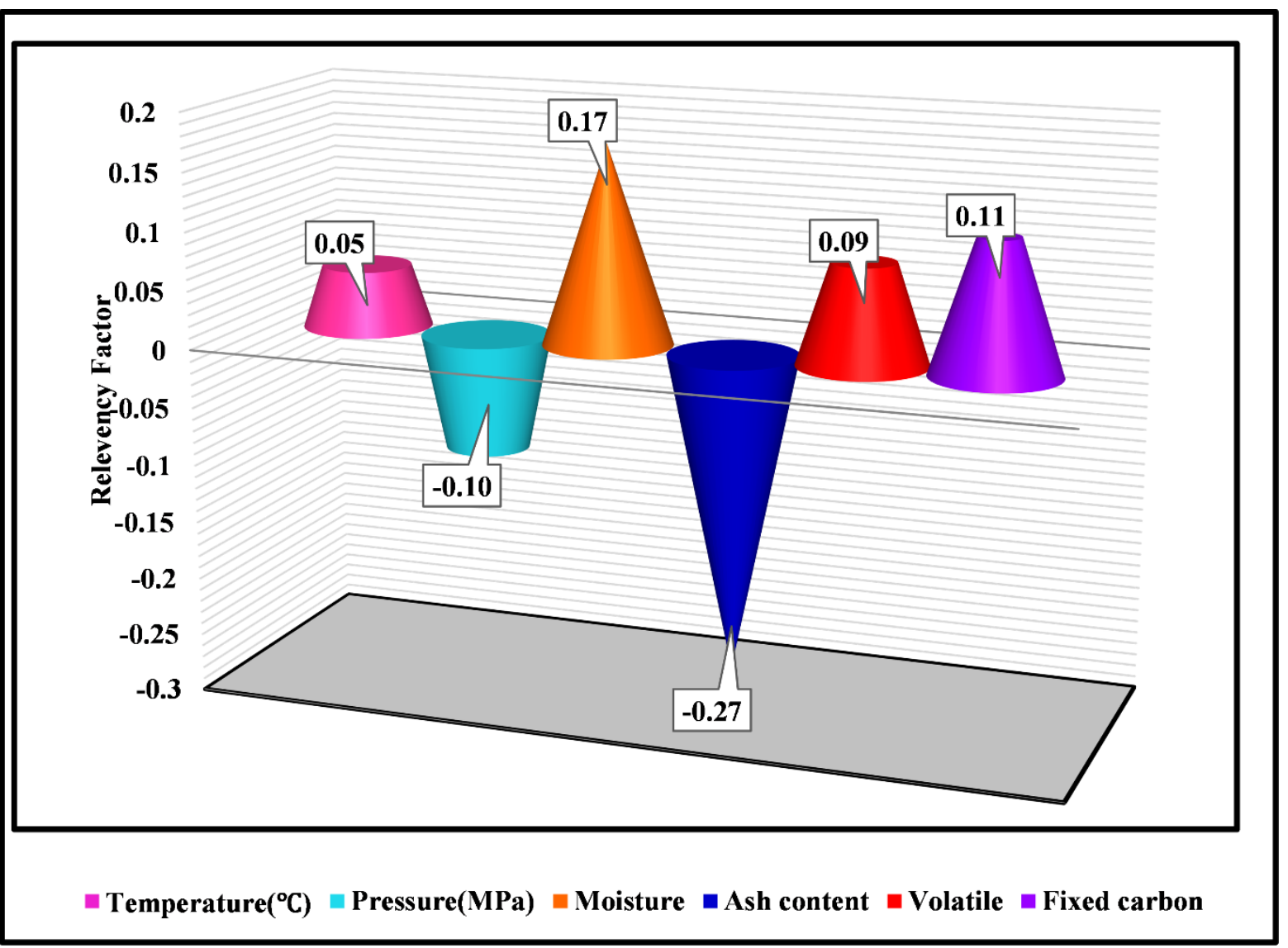

Fig. 8: Investigation of effect of different parameters on excess adsorption of $\mathrm{CO}_{2}$

\section{Conclusions}

In the current work, we have utilized four different kernel functions including Exponential, Square exponential, Matern and Rational Quadratic in Gaussian Process Regression algorithm in order to calculate excess adsorption of $\mathrm{CO}_{2}$ on various kinds of coal bed. A comprehensive databank of $\mathrm{CO}_{2}$ adsorption on various kinds of coal seams including 394 real data point in wide range of conditions is collected for preparation and validation of algorithms. The comparison of GPR models and collected data expresses that suggested models have great accuracy and also the Exponential GPR model has better performance than other ones. For this structure, $R^{2}=1, M R E=0.01542, M S E=0$, RMSE $=0.00019$ and STD=0.00014 have been calculated. The interesting point of these models is overcoming the limitation of coal types. Additionally, the effects of inputs on adsorption of $\mathrm{CO}_{2}$ on coal seams have been investigated in detail for the first time.

\section{References}

1. Meng, M.; Qiu, Z.; Zhong, R.; Liu, Z.; Liu, Y.; Chen, P. Adsorption characteristics of supercritical co2/ch4 on different types of coal and a machine learning approach. Chemical Engineering Journal 2019, 368, 847-864.

2. Pashin, J.C.; McIntyre, M.R. Temperature-pressure conditions in coalbed methane reservoirs of the black warrior basin: Implications for carbon sequestration and enhanced coalbed methane recovery. International Journal of Coal Geology 2003, 54, 167-183. 
3. GALE, J.J. Using coal seams for co2 sequestration. Geologica Belgica 2004.

4. Mazzotti, M.; Pini, R.; Storti, G. Enhanced coalbed methane recovery. The Journal of Supercritical Fluids 2009, 47, 619-627.

5. Meng, M.; Qiu, Z. Experiment study of mechanical properties and microstructures of bituminous coals influenced by supercritical carbon dioxide. Fuel 2018, 219, 223-238.

6. Lebedev, M.; Zhang, Y.; Sarmadivaleh, M.; Barifcani, A.; Al-Khdheeawi, E.; Iglauer, S. Carbon geosequestration in limestone: Pore-scale dissolution and geomechanical weakening. International Journal of Greenhouse Gas Control 2017, 66, 106-119.

7. Ramasamy, S.; Sripada, P.P.; Khan, M.M.; Tian, S.; Trivedi, J.; Gupta, R. Adsorption behavior of co2 in coal and coal char. Energy \& Fuels 2014, 28, 5241-5251.

8. Zhang, J.; Liu, K.; Clennell, M.; Dewhurst, D.; Pervukhina, M. Molecular simulation of co2ch4 competitive adsorption and induced coal swelling. Fuel 2015, 160, 309-317.

9. De Silva, P.N.K.; Ranjith, P. Understanding and application of co2 adsorption capacity estimation models for coal types. Fuel 2014, 121, 250-259.

10. Li, D.; Liu, Q.; Weniger, P.; Gensterblum, Y.; Busch, A.; Krooss, B.M. High-pressure sorption isotherms and sorption kinetics of ch4 and co2 on coals. Fuel 2010, 89, 569-580.

11. Kim, H.J.; Shi, Y.; He, J.; Lee, H.-H.; Lee, C.-H. Adsorption characteristics of co2 and ch4 on dry and wet coal from subcritical to supercritical conditions. Chemical Engineering Journal 2011, 171, 45-53.

12. Bae, J.-S.; Bhatia, S.K. High-pressure adsorption of methane and carbon dioxide on coal. Energy \& Fuels 2006, 20, 2599-2607.

13. Krooss, B.v.; Van Bergen, F.; Gensterblum, Y.; Siemons, N.; Pagnier, H.; David, P. Highpressure methane and carbon dioxide adsorption on dry and moisture-equilibrated pennsylvanian coals. International Journal of Coal Geology 2002, 51, 69-92.

14. Tang, X.; Ripepi, N. High pressure supercritical carbon dioxide adsorption in coal: Adsorption model and thermodynamic characteristics. Journal of CO2 Utilization 2017, 18, 189-197.

15. Toribio, M.; Oshima, Y.; Shimada, S. Evaluation of sequesterable carbon dioxide in japanese coal samples at sub-critical and supercritical conditions. In Studies in surface science and catalysis, Elsevier: 2004; Vol. 153, pp 375-380.

16. Siemons, N.; Busch, A. Measurement and interpretation of supercritical co2 sorption on various coals. International Journal of Coal Geology 2007, 69, 229-242.

17. Ottiger, S.; Pini, R.; Storti, G.; Mazzotti, M.; Bencini, R.; Quattrocchi, F.; Sardu, G.; Deriu, G. Adsorption of pure carbon dioxide and methane on dry coal from the sulcis coal province (sw sardinia, italy). Environmental Progress 2006, 25, 355-364.

18. Sakurovs, R.; Day, S.; Weir, S.; Duffy, G. Application of a modified dubinin- radushkevich equation to adsorption of gases by coals under supercritical conditions. Energy $\&$ fuels 2007, 21, 992-997.

19. Day, S.; Duffy, G.; Sakurovs, R.; Weir, S. Effect of coal properties on co2 sorption capacity under supercritical conditions. International Journal of Greenhouse Gas Control 2008, 2, 342-352.

20. Pini, R.; Ottiger, S.; Burlini, L.; Storti, G.; Mazzotti, M. Sorption of carbon dioxide, methane and nitrogen in dry coals at high pressure and moderate temperature. International Journal of Greenhouse Gas Control 2010, 4, 90-101. 
21. Luo, X.; Wang, S.; Wang, Z.; Jing, Z.; Lv, M.; Zhai, Z.; Han, T. Adsorption of methane, carbon dioxide and their binary mixtures on jurassic shale from the qaidam basin in china. International Journal of Coal Geology 2015, 150, 210-223.

22. Song, Y.; Xing, W.; Zhang, Y.; Jian, W.; Liu, Z.; Liu, S. Adsorption isotherms and kinetics of carbon dioxide on chinese dry coal over a wide pressure range. Adsorption 2015, 21, 53-65.

23. Rasmussen, C.E. In Gaussian processes in machine learning, Summer School on Machine Learning, 2003; Springer: pp 63-71.

24. Richardson, R.R.; Osborne, M.A.; Howey, D.A. Gaussian process regression for forecasting battery state of health. Journal of Power Sources 2017, 357, 209-219.

25. Cai, H.; Jia, X.; Feng, J.; Li, W.; Hsu, Y.-M.; Lee, J. Gaussian process regression for numerical wind speed prediction enhancement. Renewable Energy 2020, 146, 2112-2123.

26. Razavi, R.; Bemani, A.; Baghban, A.; Mohammadi, A.H.; Habibzadeh, S. An insight into the estimation of fatty acid methyl ester based biodiesel properties using a lssvm model. Fuel 2019, 243, 133-141.

27. Bemani, A.; Baghban, A.; Mohammadi, A.H. An insight into the modeling of sulfur solubility of sour gases in supercritical region. Journal of Petroleum Science and Engineering 2019, 106459.

28. Razavi, R.; Sabaghmoghadam, A.; Bemani, A.; Baghban, A.; Chau, K.-w.; Salwana, E. Application of anfis and lssvm strategies for estimating thermal conductivity enhancement of metal and metal oxide based nanofluids. Engineering Applications of Computational Fluid Mechanics 2019, 13, 560-578.

29. Baghban, A.; Kahani, M.; Nazari, M.A.; Ahmadi, M.H.; Yan, W.-M. Sensitivity analysis and application of machine learning methods to predict the heat transfer performance of cnt/water nanofluid flows through coils. International Journal of Heat and Mass Transfer 2019, 128, 825-835.

30. Baghban, A.; Kardani, M.N.; Mohammadi, A.H. Improved estimation of cetane number of fatty acid methyl esters (fames) based biodiesels using tlbo-nn and pso-nn models. Fuel 2018, 232, 620-631.

31. Baghban, A.; Adelizadeh, M. On the determination of cetane number of hydrocarbons and oxygenates using adaptive neuro fuzzy inference system optimized with evolutionary algorithms. Fuel 2018, 230, 344-354.

32. Zarei, F.; Rahimi, M.R.; Razavi, R.; Baghban, A. Insight into the experimental and modeling study of process intensification for post-combustion co2 capture by rotating packed bed. Journal of cleaner production 2019, 211, 953-961.

33. Baghban, A.; Pourfayaz, F.; Ahmadi, M.H.; Kasaeian, A.; Pourkiaei, S.M.; Lorenzini, G. Connectionist intelligent model estimates of convective heat transfer coefficient of nanofluids in circular cross-sectional channels. Journal of Thermal Analysis and Calorimetry 2018, 132, 12131239. 